\title{
A population-based survey of visual impairment and its correlates in Mahabubnagar district, Telangana State, India
}

\section{Running head: Visual Impairment Survey in Mahabubnagar district India}

Islay Mactaggart ${ }^{1}$, Sarah Polack ${ }^{1}$, GVS Murthy ${ }^{1,2}$, Hannah Kuper $^{1 *}$

${ }^{1}$ International Centre for Evidence in Disability, London School of Hygiene \& Tropical Medicine, Keppel Street, London WC1E 7HT, UK

2 Indian Institute of Public Health, Plot No \#1, A.N.V. Arcade, Amar Co-op

Society, Kavuri Hills, Madhapur, Hyderabad, 500033, India

*Author for correspondence. E-mail: Hannah.kuper@Ishtm.ac.uk

Financial support: This research was supported by a grant from CBM.

Conflict of interest: None of the following authors have any proprietary interests or conflicts of interest related to this submission.

This paper has not been published anywhere previously and is not being considered for another publication, nor has it been reviewed by another journal. 


\section{Abstract}

Purpose: To estimate the prevalence and correlates of visual impairment in Mahabubnagar district, Telangana, India.

Methods: Fifty-one clusters of 80 people (all ages) were sampled with probability proportionate to size. Households within clusters were selected through compact segment sampling. Visual acuity (VA) was measured with a tumbling "E" chart. An Ophthalmic Assistant or Vision Technician examined people with $\mathrm{VA}<6 / 12$ in either eye. Other impairments (hearing, physical) were clinically assessed and self-reported functional difficulties measured using the Washington Group Extended Set. People with visual impairment and age-sex matched controls with normal vision were interviewed about poverty, employment and education.

Results: 4,125 people were enumerated and 3,574 screened ( $86.6 \%)$. The prevalence of visual impairment $(\mathrm{VA}<6 / 12)$ was $8.0 \%(95 \% \mathrm{CI}=6.9-9.4 \%)$ and blindness was $0.4 \%(0.2-0.9 \%)$, and both increased rapidly with age. Uncorrected refractive error was the leading cause of visual impairment, and cataract the leading cause of blindness. Cataract surgical coverage (proportion of all cataracts that had received surgery) was relatively low ( $41 \%$ of people at VA<6/60), while post-surgery outcomes were good ( $81 \%$ of operated eyes had presenting $V A \geq 6 / 18$ ). Among the 287 people with visual impairment, $15 \%$ had a moderate/severe physical impairment or epilepsy and $25 \%$ had a moderate/severe hearing impairment. Self-reported difficulties in vision were relatively closely related to visual acuity. People with visual impairment were 
more likely to be in the poorest quartile $(\mathrm{OR}=1.9,95 \% \mathrm{CI}=1.0-3.4)$ or unemployed $(5.0,2.2-10.0)$, compared to controls.

Conclusions: Visual impairment was common in Mahabubnagar district, was mostly avoidable, and was correlated with poverty markers. 


\section{INTRODUCTION}

India is home to 8.08 million blind people; one in five blind people globally. ${ }^{1}$ Many surveys on the prevalence and causes of blindness among older people in India have been conducted in recent years, ${ }^{2-9}$ largely due to the widespread use of the Rapid Assessment of Avoidable Blindness (RAAB) and custom-made variations of this survey method. ${ }^{2,3,6-9}$ RAAB surveys focus on people aged 50 and above, and use simple examination protocols, so are relatively cheap and fast to conduct. Consequently, more than 200 RAAB surveys have been conducted to date, including many in India. However, few surveys in India have included people across all age groups, ${ }^{10}$ and consequently little is known about the prevalence and causes of visual impairment in people younger than 50 years. Furthermore, while data on self-reported difficulties with vision are widely collected, including in the India census of 2011 , it is not known how this relates to visual acuity in this setting.

There are also other important gaps in our knowledge about visual impairment in India. Older people are more vulnerable to visual impairment, but also to other types of impairments, such as physical or hearing impairments. However, few studies have measured the overlap between these conditions, even though this information is needed to plan appropriate services. For instance, tackling cataract blindness remains an important priority of eye care programmes in India. ${ }^{11}$ Uptake of cataract services among those who need them is often low, as

a result of a range of barriers. It is likely that people with other impairments, such as hearing or physical, may find it more difficult to access cataract services 
and so adjustments may need to be made to how the services are provided. On a separate issue, there are strong reasons to believe that reducing the prevalence of blindness and visual impairment will reap economic benefits, as people are more likely to work and require less assistance from family members. 12,1314 This information is needed to advocate for the provision of more eye care services. However, the relationship of blindness with employment and poverty has not been investigated widely, including in India. 9,15

We conducted an all-age population-based survey to estimate the prevalence of visual impairment in Mahabubnagar district, Telangana State, India. Within the context of this study we also assessed the agreement between objective clinical measures and self-reported measures of visual loss, the relationship between vision and other impairments, and the association between visual impairment and markers of poverty. 


\section{MATERIALS AND METHODS}

\section{Sampling}

Data collection was undertaken during February-April 2014 in Mahabubnagar district, Telangana State (previously part of Andhra Pradesh), India. The expected prevalence of vision impairment (VA<6/18 all ages) was estimate for India $5 \%$ based on WHO data, and so we used the highly conservative estimate of $4 \%$ for prevalence of $\mathrm{VA}<6 / 12 .{ }^{1}$ This required a sample of 4,056 , assuming precision of $20 \%, 95 \%$ confidence, a design effect of 1.5 and $20 \%$ nonresponse.

We used a two-stage sampling procedure. Fifty-one clusters of 80 people were selected using probably proportionate to size sampling. A cluster size of 80 was selected as during the pilot phase this was the number feasible for completion during a 2 day period. We used the 2011 census data as the sampling frame. Within clusters, households were selected using compact segment sampling. ${ }^{16}$ Existing maps or sketch maps were drawn by team members in collaboration with community leaders, showing the approximate distribution of the population. Maps were then divided into segments of approximately 80 people and one segment was randomly selected. The enumerators visited all households door-to-door in that segment until 80 people (all ages) were enumerated.

At the household, a roster was compiled to record the name, age, sex and contact details of each household member. Household members were informed about the survey and invited to attend a screening clinic at a previously identified central location over the next two days. If an eligible person did not 
attend the clinic the enumerators visited their household at least twice to encourage attendance. If they were unable to travel to the clinic (e.g. due to mobility impairment) the survey team visited them at their household at the end of the second day, though this was a rare event (exact numbers not recorded).

\section{Screening for visual impairment}

All participants attending the clinic were screened for visual impairment by an ophthalmic assistant or vision technician: For participants aged $>5$ years visual acuity (VA) was assessed using a tumbling ' $E$ ' chart with $6 / 12,6 / 18$ and $6 / 60$ size optotypes. Pinhole vision was assessed if vision was $<6 / 12$ in either eye. Vision was categorised according to the presenting vision in the better eye as follows:

- Blind: $V A<3 / 60$

- Severely visually impaired: $V A<6 / 60$ but $\geq 3 / 60$

- Moderately visually impaired: VA $<6 / 18$ but $\geq 6 / 60$

- Early visual impairment: $V A<6 / 12$ but $\geq 6 / 18$

- Normal vision: $V A \geq 6 / 12$

For children aged under 2 years vision was assessed by an Ophthalmic Assistant or Vision Technician using the fix and follow method. For children aged 2-4 years counting fingers was used whereby the child was asked to count or copy the number of fingers held up by the assistant/technician standing at 6 meters. Children who failed these tests were counted as having a vision impairment $(V A<6 / 12)$. Severity level of impairment for children under 5 was not assessed. 
The lens status of all participants was assessed using a torch and direct ophthalmoscope. All people with presenting $\mathrm{VA}<6 / 12$ had their eyes examined by the ophthalmic assistant/vision technician using a direct ophthalmoscope to determine the cause of vision loss (classified as: refractive error, cataract, other). Data were also collected on details of cataract surgery and reasons for not undergoing cataract surgery where relevant.

\section{Assessment of hearing and physical impairment and self-reported difficulties}

In addition, participants were also screened for hearing and physical impairments and self-reported functional difficulties (main findings reported elsewhere). ${ }^{17}$

Hearing: Initial screening of all participants was conducted through an optoacoustic emissions (OAE) hearing test to assess middle ear function in both ears. Participants who failed this test in both ears or for whom an OAE reading could not be taken underwent Pure Tone Audiometry (PTA) Screening to assess the level of hearing impairment. Hearing in each ear was measured at $1 \mathrm{KHz}, 2 \mathrm{KHz}, 4 \mathrm{KHz}, 0.5 \mathrm{KHz}$ and again at $1 \mathrm{KHz}$ to ensure consistency of response and the average reading for each ear across the 4 frequencies was recorded. Children $<4$ years underwent OAE testing only, as PTA is not feasible for this age group. Hearing impairment was categorised as $>41 \mathrm{db}$ (adults aged $>18$ years) or $>35 \mathrm{db}$ (children $\leq 18$ years) 
Physical impairment and epilepsy: Seven initial screening questions were used to assess a)difficulty using the musculoskeletal system b)use of mobility aid

c)whether the participant considers any body part to be misshapen and d) whether they have experienced seizures or have chronic back pain. ${ }^{18}$ Any participant answering "yes" to at least one question was examined by a physiotherapist to determine whether there was a moderate/severe physical impairment and/or epilepsy using a structured examination tool. These questions had been translated and back-translated into Telugu to ensure content relevance.

Self-reported difficulties: Self-reported difficulties in vision were assessed using the vision question from the Washington Group extended set of questions: "Do you have difficulty seeing, even if wearing glasses?" (for glasses wearers) or "Do you have difficulty seeing" (for non-glasses wearers), with possible answers given as "no difficulty", "some difficulty", "a lot of difficulty" and "cannot do at all". ${ }^{19}$ In addition, using the same tool people were asked if they had difficulty in hearing, walking/climbing steps, remembering/concentrating, washing/dressing, communicating or upper body indicators. People were classified as having a disability if they reported "a lot of difficulty" or "cannot do at all" in at least one domain.

\section{Case-control study:}

All people with moderate or worse visual impairment $(\mathrm{VA}<6 / 18)$ identified in the survey and/or reporting a lot of difficulty with at least one the domains listed above from the Washington Group tool were defined as having a disability 
("cases"). For every case, one age- sex-matched control with normal vision, and no other impairments or self-reported functional limitations from the same cluster was selected. Cases and controls underwent in depth interviews using a semi-structured questionnaire. The questionnaire included items on poverty, education and employment.

\section{Training}

Three survey teams each consisting of 1 visual technician or ophthalmic assistant, 1 audiologist, 1 physiotherapist, 2 enumerators, 3 field assistants and 2 interviewers received 10 days training. The inter-observer variation for the measurement of vision, hearing and physical impairment level and diagnosis of cause was assessed to ensure it was of an acceptable standard (i.e. Kappa $\geq 0.6$ ) at the end of training. The questionnaires were cognitively tested and checked for context relevance, and the survey protocol was pilot tested for suitability. Ongoing data collection was monitored by the project coordinator (IM) throughout the data collection period.

\section{Data analysis}

Data were analysed using STATA. The 'svy' command was used to derive prevalence estimates accounting for the cluster sampling design. The CSC per person was calculated as: (Number of persons with unilateral or bilateral aphakia)/ (number of persons with unilateral or bilateral aphakia + number of persons with bilateral cataract causing $<6 / 60$ vision). We constructed a socioeconomic status score through principal component analysis (PCA) of 
household assets. The PCA score distribution for controls was used to define the interquartile range, with cases then categorised into quartiles based on control "cut-points". Logistic regression analyses were undertaken to assess the relationship between visual impairment and poverty, employment and education. These analyses were adjusted for age and sex, as matching was not complete and so conditional logistic regression analyses could not be undertaken. Sensitivity analysis was undertaken comparing reported difficulties seeing to VA. For the purposes of assessing agreement, VA was considered the gold standard.

\section{Ethics}

Approval for the study was granted by the following ethics boards: London School of Hygiene and Tropical Medicine (London, UK), Public Health Foundation of India Institutional Ethics Committee (India) and Government of India Health Ministry Screening Committee (India). All participants gave informed written/finger print consent to participate. For people aged $\leq 18$ years a caregiver was required to provide written/finger print consent and to remain present throughout the screening.

Basic medicines were distributed by clinical team members where appropriate (e.g. eye drops), and all participants with unmet health needs were referred to relevant services. All identified cases in the study, regardless of health or other need, were referred to a Community-based Rehabilitation (CBR) or Self Help Group program for additional support in education, livelihoods or benefits as required. 


\section{RESULTS}

In total, 4,125 people ( 51 clusters of 80 people plus 45 additional participants) were enumerated for the population-based survey, of whom 3,574 were screened (response rate $86.6 \%$ ). The age distribution of the study participants was similar to the Census estimates for the District (Table 1). Among the nonresponders, only $0.3 \%(n=11)$ refused, whilst the remaining $13.1 \%(n=540)$ were unavailable. The mean age was higher amongst those not available (30.9 years, 29.4-32.4) and lower for those who refused (24.3 years, 14,0-34.6) compared to those who were examined (28.6 years $95 \%$ CI $27.9-29.2$ ). People who were examined were more likely to be female (52\%) compared to people who were not available (35\%) or refused to be examined (18\%). Data on visual impairment were missing for 49 (1\%) people.

The overall prevalence of visual impairment $(\mathrm{VA}<6 / 12)$ was $8.0 \%(95 \% \mathrm{CI}=6.9$ $9.4 \%)$ and blindness was $0.4 \%(0.2-0.9 \%)$ (Table 2$)$. The prevalence of both blindness and visual impairment increased rapidly with age, so that the vast majority of cases of visual impairment (79\%) and blindness (80\%) were in people aged $50+$. Extrapolating these data to the general population, per one million people there are an estimated 80,460 people with visual impairment (95\% CI: $69,000-94,000)$. The prevalence of visual impairment was higher in women $(9.0 \%, 7.7-10.5 \%)$ than in men $(7.0 \%, 5.7-8.6 \%)$.

Uncorrected refractive error was the leading cause of visual impairment. This was the case for people of all ages (57\%) as well as those aged $50+(55 \%)$ 
(Table 3). Cataract was the leading cause of blindness among people of all ages $(64 \%)$ as well as those aged $50+(75 \%)$. Causes of blindness and VI were therefore similar among people aged $>50$ years to in the total population.

The cataract surgical coverage (CSC, proportion of all cataract patients or eyes that have received cataract surgery) was moderately low. Assuming only people/eyes with $\mathrm{VA}<6 / 60$ are operated on, there were 61 people who had received surgery and 86 people with bilateral VA $<6 / 60$ from cataract identified in the survey, giving a CSC of $41 \%$ of people. For eyes, there were 102 eyes that had received surgery and 250 eyes with $V A<6 / 60$ from cataract identified in the survey, giving a CSC for $29 \%$ of eyes. Both measures of CSC were slightly higher among females than males (people: $43 \%$ versus 35\%; Eyes: $31 \%$ versus $26 \%)$. The most common place for operation was at a government hospital ( $40 \%$ of eyes), followed by an eye camp (35\%) or private hospital (24\%). Visual acuity outcome of surgery was generally good, as $81 \%$ of eyes were able to see $6 / 18$ with available correction. Poor outcome (cannot see $6 / 60$ ) was observed in $12 \%$ of eyes with available correction, which reduced to $10 \%$ after pinhole correction. Average age of operation (average across both eyes if both eyes operated) was 59.1 years and mean time since operation was 3.7 years. The most commonly cited barriers to uptake of surgery among those with visual impairment from cataract were: inability to afford surgery $(28 \%)$, lack of person to accompany them (23\%), fear of surgery $(16 \%)$ and lack of perceived need for surgery $(12 \%)$. 
Self-reported difficulties in vision were compared to clinically measured VA (Table 4). Of the 284 people with VI, 224 reported "some" or more difficulties with seeing (sensitivity $=79 \%$ ) although only 52 reported "a lot of difficulty" or more with seeing (sensitivity $=18 \%$ ). Of the 3165 people who had no VI $(\mathrm{VA} \geq 6 / 12), 2537$ reported no problem with seeing (specificity $=80 \%$ ). Of the 2596 who reported that they had no problem with seeing, 2537 also had no VI (negative predictive value of $98 \%$ ). Among 851 people who said that they had "some" or more problem with vision, 222 had VI (positive predictive value of $26 \%)$. However, if this was restricted to the group reporting "a lot of difficulty" or more then the positive predictive value increased to $43 \%$.

Among the 287 people with visual impairment, 15\% had a moderate or severe physical impairment or epilepsy and $25 \%$ had a moderate or severe hearing impairment. Among the 14 people who were blind, $21 \%$ had a physical impairment or epilepsy, $50 \%$ had a hearing impairment and $43 \%$ had another type of disability (not including vision). There was no difference in CSC between people with and without another impairment (42\% versus $41 \%$ ).

There were 176 cases with visual impairment $(\mathrm{VA}<6 / 18)$ and 377 controls without visual impairment (VA>=6/18) included in the study. Cases and controls were compared with respect to socio-economic status, employment and education (Table 5). People with visual impairment were significantly more likely to be in the poorest quartile, rather than the richest, compared to people without visual impairment (age and sex adjusted $\mathrm{OR}=1.9,95 \% \mathrm{CI}, 1.0-3.4$ ). People with visual impairment aged $18+$ were also significantly more likely not to have 
worked in the last 12 months $(O R=5.0,3.3-10.0)$. The small numbers of children identified with visual impairment made it impossible to assess the relationship between visual impairment and school attendance. 


\section{Discussion}

This survey shows that the prevalence of visual impairment in this Indian setting is high, affecting approximately $8 \%$ of the population, while blindness is less common at $0.4 \%$. The prevalence of both visual impairment and blindness increase rapidly in prevalence with age, so that the vast majority of cases are found among those aged $50+$. Most cases of visual impairment (91\%) and blindness $(85 \%)$ were considered treatable as they were attributable to refractive or cataract. Cataract surgical coverage was moderately low, while outcomes of surgery were relatively good.

Few existing surveys in India have estimated the prevalence of visual impairment for people of all ages, making comparison with the existing literature difficult. One exception is a large survey in Andhra Pradesh that put the prevalence of blindness in all ages at $1.34 \%$, therefore three times as high in the current study, although this estimate did include people with visual field constriction, ${ }^{10}$ and was published in 2001 , before the substantial scale-up in eye care services. This present survey estimated that the prevalence of blindness in those aged $50+$ was $1.8 \%$, and for moderate/severe visual impairment (VA<6/18) was $14.8 \%$. Our prevalence estimates are in line with previous Rapid Assessment of Avoidable Blindness (RAAB) surveys among people aged $50+$ in India, 2, 3, 6, 8 but in general lower than estimates for surveys undertaken in Andhra Pradesh State (formerly included Telangana State) ${ }^{20}$ although several of these surveys are not recent. Our findings on causes of blindness and visual impairment are also in accord with the existing literature. Previous surveys consistently show that the main cause of blindness is cataract, ${ }^{2-4,7-9}$ while 
cataract and uncorrected refractive errors are commonly the main causes of visual impairment. 2, 4,7 Posterior segment disease has not emerged as a primary cause of blindness in India, potentially because of the low cataract surgical coverage or else because most surveys use the WHO protocol for classifying cause of visual loss, so that the cause that is most amenable to treatment or prevention will be recorded as the primary cause. Anterior segment causes, such as cataract and refractive error will therefore be documented in preference to posterior segment causes, where there are multiple causes present.

Consequently, posterior segment conditions are likely to be underestimated in most surveys, including potentially in this study as anterior segment diseases are preferentially ascribed as the primary cause of vision loss.

The majority of people with blindness or visual impairment were aged 50 and above, and consequently the causes of blindness and visual impairment in this age group were reflective of the status of the whole population. This provides further support for the continued use of RAAB, which focusses on people aged $50+$ only, for assessing the status of vision and causes of visual loss in the Indian population. The rationale for this focus on people aged $50+$ is that the prevalence of VI is highest in this age group so that a smaller sample size is required for surveys, yet the causes of VI reflect those of the population of all ages, allowing planning of public health strategies. These results therefore tally with those previously made using data from the Gambia, which also supported the use of surveys in people aged $50+$ for assessing visual impairment prevalence in populations. ${ }^{21}$ Indeed, the current study would have been more efficient if it had included only people aged 50 and above, yet the decision was made to include people of all ages as the study had broader aims to assess 
physical and hearing impairment and self-reported difficulties across the entire population.

Self-reported difficulties in vision were relatively closely related to clinical measures of visual impairment. Other studies have also noted the strong positive relationship between visual acuity and self-rated vision. ${ }^{22,}{ }^{23}$ However, relying only on self-reported measures only would mean that $27 \%$ of people with visual impairment would not have been identified as having difficulties with vision. Furthermore, $74 \%$ of people reporting difficulties with vision do not have a mild or worse visual impairment and so self-reported measures may overestimate visual problems in the population. This discrepancy between selfreported and clinical measures of vision may be because self-rated vision is related to other aspects of visual function besides VA, including difficulties with near vision, contrast sensitivity, stereoacuity and visual fields, not captured through visual acuity. Self-reported measures of difficulties with vision therefore cannot replace visual acuity assessment, and reasons for the discrepancy in these measures deserves further exploration.

A key finding from this study is that the prevalence of physical and hearing impairments, or functional difficulties in other domains, was high among the people with visual impairment. This finding is unsurprising, since the prevalence of all impairments increases strongly with age, yet few other studies have assessed the occurrence of multiple impairments. This association is important to note, since people with functional difficulties in multiple domains may find it difficult to access eye care services, highlighting for the need for inclusive eye 
health and policy and service-level prioritisation. However, the lack of difference in CSC between people with and without other impairments suggests that this is not a key driver of lack of uptake of cataract surgery.

Visual impairment was related to both poverty and lack of employment in this study. These patterns are expected and have been reported previously across the globe. ${ }^{12} 2425$ Data on this association from India have been lacking with the exception of a large survey in Andhra Pradesh which showed a relationship between blindness and decreasing socioeconomic status. ${ }^{10}$ One study in India did show a positive impact of cataract surgery on household income and employment. ${ }^{15}$

There were a number of limitations to the study. Determination of cause of vision loss was made by a visual technician or ophthalmic assistant in the field, rather than ophthalmologists who have a higher level of skill and experience, and they had limited equipment available (direct ophthalmoscope). As a consequence, it was difficult to determine specific causes of posterior segment disease or to assess visual acuity in young children. Few children with visual impairment were identified making the study under-powered to determine the relationship with educational attendance. It was beyond the scope of the current paper to report prevalence of visual, hearing, physical impairment and selfreported difficulties, and so these are presented as separate papers. ${ }^{17} \mathrm{~A}$ design effect of 1.5 was selected for calculation of the sample size required, as was used in the majority of surveys conducted in India. However, a higher design effect would have been preferable, given the large cluster size used, and indeed 
the actual design effect was 1.8 for visual impairment. However, the prevalence of visual impairment was higher than anticipated ( $8 \%$ versus $4 \%$ ), and so the study remained adequately powered. In some circumstances, all remaining household members were included in the survey so that the cluster size at times exceeded 80 , even though this was not the original protocol. In total, 45 additional participants were included, and this may have introduced some bias, although would not have impacted greatly on the overall findings. There were also important strengths. The study was population-based and included people of all ages, in contrast to RAAB studies which focus on people aged $>50$ years. Data were also collected on other impairments, including hearing and physical impairment, as well as on self-reported difficulties with seeing.

In conclusion, visual impairment was relatively common in this district in India. Most cases of visual impairment and blindness were avoidable, suggesting the need to further scale up eye care services. Visual impairment was related to low socio-economic status and lack of employment, suggesting that provision of eye care services may ultimately be poverty alleviating. ${ }^{13}$ 
Table 1. Age and gender distribution of Mahbubnagar District (2011 census) and study sample population*

\begin{tabular}{|c|c|c|c|c|c|c|}
\hline \multirow[b]{2}{*}{$\begin{array}{l}\text { Age } \\
\text { group }\end{array}$} & \multicolumn{2}{|c|}{ Males } & \multicolumn{2}{|c|}{ Females } & \multicolumn{2}{|l|}{ Total } \\
\hline & $\begin{array}{c}\text { District } \\
(n=2,036,100)\end{array}$ & $\begin{array}{c}\text { Study } \\
\text { sample } \\
(n=1708)\end{array}$ & $\begin{array}{c}\text { District } \\
(n=1,989,600)\end{array}$ & $\begin{array}{c}\text { Study } \\
\text { sample } \\
(n=1866)\end{array}$ & $\begin{array}{c}\text { District } \\
(n=4,025,800)\end{array}$ & $\begin{array}{c}\text { Study } \\
\text { sample } \\
(n=3574)\end{array}$ \\
\hline $0-9$ & $20 \%$ & $21 \%$ & $19 \%$ & $18 \%$ & $19 \%$ & $19 \%$ \\
\hline $10-19$ & $21 \%$ & $21 \%$ & $20 \%$ & $17 \%$ & $21 \%$ & $19 \%$ \\
\hline $20-29$ & $18 \%$ & $16 \%$ & $19 \%$ & $19 \%$ & $18 \%$ & $18 \%$ \\
\hline $30-39$ & $15 \%$ & $13 \%$ & $15 \%$ & $15 \%$ & $15 \%$ & $14 \%$ \\
\hline $40-49$ & $11 \%$ & $11 \%$ & $10 \%$ & $11 \%$ & $11 \%$ & $11 \%$ \\
\hline $50-59$ & $7 \%$ & $8 \%$ & $7 \%$ & $9 \%$ & $7 \%$ & $9 \%$ \\
\hline $60-69$ & $5 \%$ & $7 \%$ & $6 \%$ & $6 \%$ & $6 \%$ & $7 \%$ \\
\hline $70-79$ & $2 \%$ & $2 \%$ & $2 \%$ & $2 \%$ & $2 \%$ & $2 \%$ \\
\hline $80+$ & $1 \%$ & $1 \%$ & $1 \%$ & $1 \%$ & $1 \%$ & $1 \%$ \\
\hline
\end{tabular}


Table 2. Prevalence of visual impairment by age, gender and severity

\begin{tabular}{|c|c|c|c|c|c|c|c|c|c|c|c|c|}
\hline \multirow[b]{2}{*}{$\begin{array}{l}\text { Vision } \\
\text { impairment } \\
\text { category }\end{array}$} & \multicolumn{2}{|c|}{$\begin{array}{l}\text { Total } \\
(n=3567)\end{array}$} & \multicolumn{2}{|c|}{$\begin{array}{l}0-17 \text { years* } \\
(n=1222)\end{array}$} & \multicolumn{2}{|c|}{$\begin{array}{l}18-49 \text { years } \\
(n=1680)\end{array}$} & \multicolumn{2}{|c|}{$\begin{array}{l}50+\text { years } \\
(n=665)\end{array}$} & \multicolumn{2}{|c|}{$\begin{array}{l}\text { Male } \\
(n=1705)\end{array}$} & \multicolumn{2}{|c|}{$\begin{array}{l}\text { Female } \\
(n=1862)\end{array}$} \\
\hline & $\mathbf{N}$ & $\begin{array}{l}\%(95 \% \\
\mathrm{CI})\end{array}$ & $\mathbf{N}$ & $\begin{array}{l}\%(95 \% \\
\mathrm{CI})\end{array}$ & $\mathbf{N}$ & $\begin{array}{l}\%(95 \% \\
\mathrm{CI})\end{array}$ & $\mathbf{N}$ & $\%(95 \% \mathrm{CI})$ & $\mathbf{N}$ & $\begin{array}{l}\%(95 \% \\
\text { CI) }\end{array}$ & $\mathbf{N}$ & $\%(95 \% \mathrm{CI})$ \\
\hline $\begin{array}{l}\text { Mild VI; } \\
\text { VA<6/12 but } \\
>6 / 18\end{array}$ & 163 & $\begin{array}{l}5.1(4.1- \\
6.2)\end{array}$ & 0 & - & 34 & $\begin{array}{l}2.0(1.3- \\
3.1)\end{array}$ & 129 & $\begin{array}{l}19.3(15.9- \\
23.3)\end{array}$ & 71 & $\begin{array}{l}4.6(3.5- \\
6.1)\end{array}$ & 92 & $\begin{array}{l}5.5(4.4- \\
6.7)\end{array}$ \\
\hline $\begin{array}{l}\text { Moderate or } \\
\text { severe VI; } \\
\text { VA<6/18 but } \\
>3 / 60\end{array}$ & 107 & $\begin{array}{l}3.3(2.6- \\
4.3)\end{array}$ & 3 & $\begin{array}{c}0.3(0.1- \\
1.0)\end{array}$ & 17 & $\begin{array}{l}1.0(0.6- \\
1.7)\end{array}$ & 87 & $\begin{array}{l}13.0(9.8- \\
17.2)\end{array}$ & 43 & $\begin{array}{l}2.8(1.9- \\
4.1)\end{array}$ & 64 & $\begin{array}{l}3.8(2.9- \\
5.0)\end{array}$ \\
\hline Blind; $V A<3 / 60$ & 14 & $\begin{array}{l}0.4(0.2- \\
0.9)\end{array}$ & 0 & - & 2 & $\begin{array}{l}0.1(0.03- \\
0.5)\end{array}$ & 12 & $1.8(0.9-3.5)$ & 5 & $\begin{array}{l}0.3(0.1- \\
0.9)\end{array}$ & 9 & $\begin{array}{l}0.5(0.2- \\
1.1)\end{array}$ \\
\hline
\end{tabular}




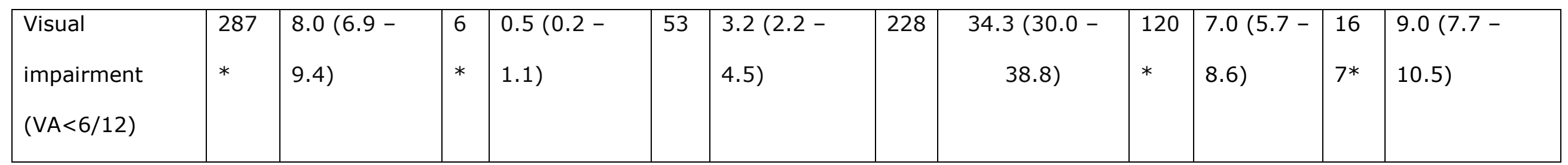

* Severity Estimates for vision are restricted to $>4$ years (NB of 6 cases 0-17, no severity data for 3: 2 are under 4 years and one has listed intellectual impairment so used counting fingers not $E$ chart) 
Table 3. Causes of visual impairment and blindness

\begin{tabular}{|l|l|l|l|l|}
\hline & \multicolumn{2}{|l|}{ People aged 50+ } & \multicolumn{2}{l|}{ All ages } \\
\hline & $\begin{array}{l}\text { Blindness (VA<3/60) } \\
(n=12)\end{array}$ & $\begin{array}{l}\text { Visual impairment } \\
(\text { VA<6/12) } \\
(n=228) *\end{array}$ & $\begin{array}{l}\text { Blindness (VA<3/60) } \\
(n=14)\end{array}$ & $\begin{array}{l}\text { Visual impairment } \\
(\text { VA<6/12) } \\
(n=287)\end{array}$ \\
\hline Refractive error & $3(25 \%)$ & $125(55 \%)$ & $3(21 \%)$ & $163(57 \%)$ \\
\hline Cataract & $9(75 \%)$ & $90(40 \%)$ & $9(64 \%)$ & $98(34 \%)$ \\
\hline Other & 0 & $12(3 \%)$ & $2(14 \%)$ & $26(9 \%)$ \\
\hline
\end{tabular}

*Data missing for one case 
Table 4. Comparison of clinically measured visually acuity and self-reported vision

\begin{tabular}{|c|c|c|c|c|c|}
\hline & \multicolumn{4}{|c|}{ Self-reported difficulties } & \\
\hline & None & Some & A lot & $\begin{array}{l}\text { Extreme/Cannot } \\
\text { do }\end{array}$ & \\
\hline Level of vision & & & & & \\
\hline No visual impairment & $\begin{array}{l}2537 \\
(80 \%)\end{array}$ & $591(19 \%)$ & $37(1 \%)$ & 0 & $3170(100 \%)$ \\
\hline Early visual impairment & $41(25 \%)$ & $117(72 \%)$ & $5(3 \%)$ & 0 & $163(100 \%)$ \\
\hline $\begin{array}{l}\text { Moderate or severe visual } \\
\text { impairment }\end{array}$ & $17(16 \%)$ & $51(48 \%)$ & $36(34 \%)$ & $1(1 \%)$ & $107(100 \%)$ \\
\hline Blind & $1(7 \%)$ & $4(29 \%)$ & $9(64 \%)$ & 0 & $14(100 \%)$ \\
\hline Any visual impairment & $60(21 \%)$ & $172(61 \%)$ & $51(18 \%)$ & $1(1 \%)$ & $284(100 \%)$ \\
\hline
\end{tabular}


*missing severity data for three cases, denominator is ages $2+$ given that WG not asked of children $0-1$ 
Table 5. Age and sex- adjusted relationship between visual impairment (VA<6/18) with poverty, employment, and education

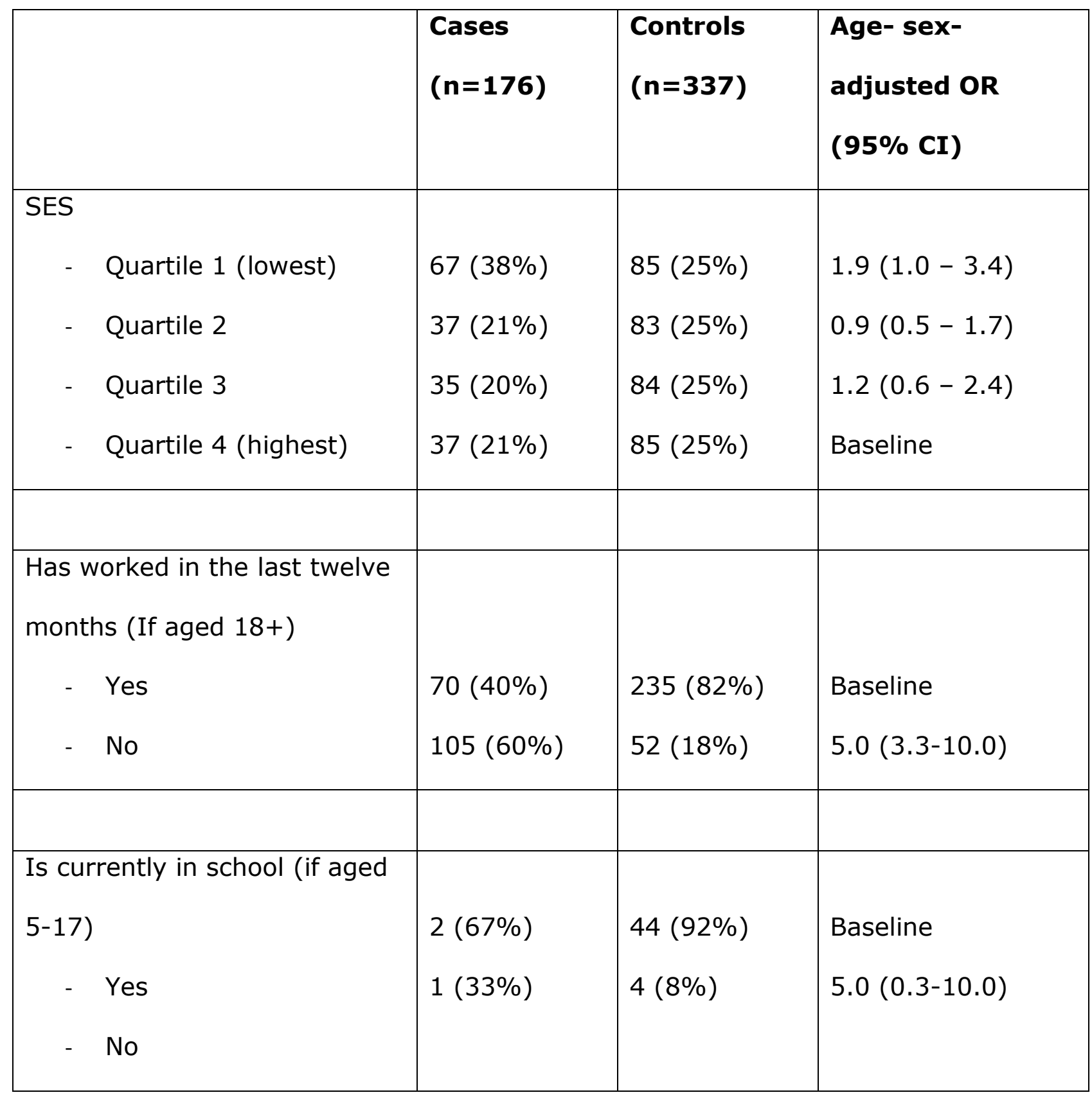




\section{REFERENCES}

1. Pascolini D, Mariotti SP. Global estimates of visual impairment: $2010 . \mathrm{Br} J$ Ophthalmol. $2012 ; 96(5): 614-8$

2. Singh N, Eeda SS, Gudapati BK, Reddy S, Kanade P, Shantha GP, et al. Prevalence and causes of blindness and visual impairment and their associated risk factors, in three tribal areas of Andhra Pradesh, India. PLoS One. 2014;9(7):e100644

3. Patil S, Gogate P, Vora S, Ainapure S, Hingane RN, Kulkarni AN, et al. Prevalence, causes of blindness, visual impairment and cataract surgical services in Sindhudurg district on the western coastal strip of India. Indian J Ophthalmol. $2014 ; 62(2): 240-5$

4. Vijaya L, George R, Asokan R, Velumuri L, Ramesh SV. Prevalence and causes of low vision and blindness in an urban population: The Chennai Glaucoma Study. Indian J Ophthalmol. 2014;62(4):477-81

5. Nangia V, Jonas JB, Gupta R, Khare A, Sinha A. Visual impairment and blindness in rural central India: the Central India Eye and Medical Study. Acta ophthalmologica. 2013;91(5):483-6

6. Dhake PV, Dole K, Khandekar R, Deshpande M. Prevalence and causes of avoidable blindness and severe visual impairment in a tribal district of Maharashtra, India. Oman journal of ophthalmology. 2011;4(3):129-34

7. Murthy GV, Vashist P, John N, Pokharel G, Ellwein LB. Prevelence and causes of visual impairment and blindness in older adults in an area of India with a high cataract surgical rate. Ophthalmic Epidemiol. 2010;17(4):185-95

8. Neena J, Rachel J, Praveen V, Murthy GV, Rapid Assessment of Avoidable Blindness India Study G. Rapid Assessment of Avoidable Blindness in India. PLoS One. $2008 ; 3(8): \mathrm{e} 2867$ 
9. Murthy GV, Gupta SK, Bachani D, Jose R, John N. Current estimates of blindness in India. Br J Ophthalmol. 2005;89(3):257-60

10. Dandona L, Dandona R, Srinivas M, Giridhar P, Vilas K, Prasad MN, et al. Blindness in the Indian state of Andhra Pradesh. Invest Ophthalmol Vis Sci. $2001 ; 42(5): 908-16$

11. Murthy G, Gupta SK, John N, Vashist P. Current status of cataract blindness and Vision 2020: the right to sight initiative in India. Indian J Ophthalmol. 2008;56(6):489-94

12. Kuper H, Polack S, Eusebio C, Mathenge W, Wadud Z, Foster A. A casecontrol study to assess the relationship between poverty and visual impairment from cataract in Kenya, the Philippines, and Bangladesh. PLoS medicine. $2008 ; 5(12): \mathrm{e} 244$

13. Kuper H, Polack S, Mathenge W, Eusebio C, Wadud Z, Rashid M, et al. Does cataract surgery alleviate poverty? Evidence from a multi-centre intervention study conducted in Kenya, the Philippines and Bangladesh. PLoS One. $2010 ; 5(11): \mathrm{e} 15431$

14. Polack S, Kuper H, Eusebio C, Mathenge W, Wadud Z, Foster A. The impact of cataract on time-use: results from a population based case-control study in Kenya, the Philippines and Bangladesh. Ophthalmic Epidemiol. $2008 ; 15(6): 372-82$

15. Finger RP, Kupitz DG, Fenwick E, Balasubramaniam B, Ramani RV, Holz FG, et al. The impact of successful cataract surgery on quality of life, household income and social status in South India. PLoS One. 2012;7(8):e44268 16. Turner AG, Magnani RJ, Shuaib M. A not quite as quick but much cleaner alternative to the Expanded Programme on Immunization (EPI) Cluster Survey design. Int J Epidemiol. 1996;25(1):198-203 
17. Ferrite S, Mactaggart I, Kuper H, Oye J, Polack S. Prevalence and causes of hearing impairment in Fundong Health District, North-West Cameroon. Trop Med Int Health. 2017;22(4):485-92

18. Atijosan $O$, Rischewski D, Simms V, Kuper $H$, Linganwa B, Nuhi A, et al. A national survey of musculoskeletal impairment in Rwanda: prevalence, causes and service implications. PLoS One. 2008;3(7):e2851

19. Madans $\mathrm{JH}$, Loeb ME, Altman BM. Measuring disability and monitoring the UN Convention on the Rights of Persons with Disabilities: the work of the Washington Group on Disability Statistics. BMC public health. 2011;11 Suppl 4:S4

20. Marmamula S, Narsaiah S, Shekhar K, Khanna RC, Rao GN. Visual impairment in the South Indian state of Andhra Pradesh: Andhra Pradesh - rapid assessment of visual impairment (AP-RAVI) project. PLoS One. $2013 ; 8(7): \mathrm{e} 70120$

21. Dineen B, Foster A, Faal H. A proposed rapid methodology to assess the prevalence and causes of blindness and visual impairment. Ophthalmic Epidemiol. 2006;13(1):31-4

22. El-Gasim M, Munoz B, West SK, Scott AW. Associations between self-rated vision score, vision tests, and self-reported visual function in the Salisbury Eye Evaluation Study. Invest Ophthalmol Vis Sci. 2013;54(9):6439-45

23. Yip JL, Khawaja AP, Broadway D, Luben R, Hayat S, Dalzell N, et al. Visual acuity, self-reported vision and falls in the EPIC-Norfolk Eye study. $\mathrm{Br} \mathrm{J}$ Ophthalmol. 2014;98(3):377-82

24. Gilbert CE, Shah SP, Jadoon MZ, Bourne R, Dineen B, Khan MA, et al. Poverty and blindness in Pakistan: results from the Pakistan national blindness and visual impairment survey. BMJ. 2008;336(7634):29-32 
25. Banks LM, Polack S. The Economic Costs of Exclusion and Gains of Inclusion of People with Disabilities. London: International Centre for Evidence in Disability, 2014. 